\title{
Do Tumor Board Recommendations Influence the Decisions of Clinicians in Planning the Treatment of Head and Neck Cancers?
}

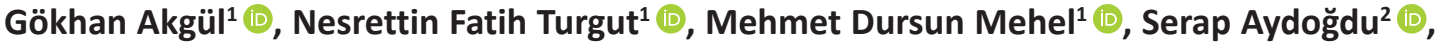 \\ Abdulkadir Özgür ${ }^{3}$ (ID
}

\begin{abstract}
${ }^{1}$ University of Health Sciences Turkey, Samsun Health Practices and Research Center, Department of Otorhinolaryngology, Samsun, Turkey ${ }^{2}$ University of Health Sciences Turkey, Samsun Health Practices and Research Center, Department of Radiation Oncology, Samsun, Turkey ${ }^{3}$ Ondokuz Mayıs University Medical Faculty, Department of Otorhinolaryngology, Samsun, Turkey
\end{abstract}

ORCID ID: G.A. 0000-0003-0699-6585; N.F.T. 0000-0001-6265-0058; M.D.M. 0000-0002-5613-3393; S.A. 0000-0002-1383-2215; A.Ö. 0000-0002-6155-5988

Citation: Akgul G, Turgut NF, Mehel MD, Aydogdu S, Ozgur A. Do tumor board recommendations influence the decisions of clinicians in planning the treatment of head and neck cancers? Tr-ENT 2021;31(2):39-44. https://doi.org/10.26650/Tr-ENT.2021.40316

\begin{abstract}
Objective: The aim of this study is to compare the decisions made at established tumor board meetings for planning the treatment of head and neck cancer patients with the individual treatment decisions of clinicians who attended the meetings.

Material and Methods: A total of 188 patients with head and neck tumors were included in this study, all of whom had been evaluated at weekly tumor board meetings at our clinic. The tumor board consisted of otolaryngologists, radiation oncologists, medical oncologists, pathologists, and radiologists. Before the board meetings, all data belonging to the patients were given to the otolaryngology surgeons and radiation oncologists who were to attend. Their treatment preferences were asked of them individually. The treatment options that clinicians recommended individually prior to board meetings were compared with the decisions made by the tumor board.

Results: It was observed that $34 \%$ (64 cases out of 188) of the individual decisions made by ENT surgeons and $34.6 \%$ (65 cases out of 188 ) of those made by radiation oncologists changed following tumor board meetings. There was a statistically significant difference between the treatment options offered individually by both ENT surgeons and radiation oncologists and the treatment recommendations made by the tumor board.

Conclusion: According to the data we obtained, the recommendations for treating patients with head and neck cancers made by the tumor boards may differ from the personal decisions of attending clinicians. Therefore, to make decisions that ensure the highest quality patient care, we believe it is necessary to evaluate all patients with head and neck tumors at multidisciplinary tumor board meetings regardless of cancer stage.
\end{abstract}

Keywords: Head and neck cancer, multidisciplinary team, tumor board

\section{INTRODUCTION}

Head and neck cancers are among the most common malignancies in the world and encompass the lips, oral cavity, salivary glands, oropharynx, nasopharynx, larynx, hypopharynx, and skin. According to a 2018 report by the International Agency for Research on Cancer, head and neck cancers comprise the seventh most common types of cancer with 890,000 new cases per year (1). Many factors, such as tumor stage, pathology evaluation, and patient comorbidity, are taken into account during cancer treatment. However, the differences in medical branches' clinical approaches and the varying clinical experience of doctors can impact treatment preferences, even when patient criteria are the same. As for all other malignancies for the last 30 years, tumor boards have played an important role in determining treatment

Corresponding Author: Gökhan Akgül E-mail: g.akgul-57@hotmail.com

Submitted: 07.05.2021 • Accepted: 02.08.2021

This work is licensed under Creative Commons Attribution-NonCommercial 4.0 International License. 
modalities for head and neck malignancies (2). The diversity and experience of tumor board members, who come from many different disciplines, have proven to be more efficient in evaluating and managing disease (3).

In the past, tumor patients were referred to the relevant surgical branch and passed on to oncology departments only if necessary (4). In addition, for patients who were considered inoperable, an oncologist's opinion was often requested regarding palliative treatment (4-6). Today, legal procedures and technological advancements in the field of chemotherapy and radiotherapy have increased the importance of a multidisciplinary approach in planning cancer patient treatment, encouraging joint decisions rather than relying solely on individual ones made by single practitioners $(3,5,7)$.

St. Thomas Aquinas said, "Quia parvus error in principio magnus est in fine" (A small error at the outset is a large one in the end) (8). Given that cancer treatment is long-term, choosing an appropriate first step in the treatment process is of paramount importance. To avoid adverse conditions during treatment, it is essential to get opinions from clinicians with different specialties and to identify all relevant care opportunities before planning treatment (9). For this reason, most cancer centers decide on patient treatment at tumor board meetings, although there is no legal requirement to do this in most countries. At our tertiary center, medical specialists dealing with cancer surgery organize tumor board meetings, where clinicians share their knowledge and experience with other professionals. In this study, the effectiveness of tumor boards was investigated by comparing the individual treatment preferences of ENT surgeons and radiation oncologists with the recommendations given by tumor boards for patients diagnosed with head and neck cancers.

\section{MATERIALS AND METHODS}

This study obtained the approval of the Samsun Research and Training Hospital Ethics committee (approval ID: 2020/0213) and evaluated the treatment modalities of patients diagnosed with head and neck cancers at our otolaryngology clinic. These cases were discussed at tumor board meetings held between January 2018 and January 2020.

At our hospital, tumor board meetings are held weekly. Board members consist of otolaryngologists, radiation oncologists, medical oncologists, radiologists, pathologists, and psychiatrists, as well as swallowing therapists, speech therapists, respiration therapists, and psychologists. Clinicians from different specialties are also invited to meetings when necessary. All patients diagnosed with head and neck cancers are discussed at the tumor board meetings regardless of cancer stage. Treatment plans are made in line with the decisions made at the meetings.

In this study, the files of all patients to be discussed at tumor board meetings containing test results, age, and gender information were provided to ENT surgeons and radiation oncologists who regularly attended tumor board meetings. Patient names were removed from the files to avoid influencing the opinions of clinicians regarding treatment. These clinicians were then asked to choose a treatment modality for the given patient from various options, such as surgery, radiotherapy (RT), chemotherapy (CT), chemoradiotherapy (CRT), followups, and additional examinations/tests (such as radiological imaging, nuclear imaging, clinical assessment, and re-biopsy). The initial treatment modalities as suggested by clinicians were compared with treatment recommendations decided by the board. The differences between these decisions were also evaluated according to tumor stage.

Patients who were to be operated on in the first tumor board were evaluated as new patients in the postoperative tumor board. Therefore, surgery and adjuvant CRT were classified separately for the same patient. However, patients who were discussed at tumor board meetings after they had completed additional tests were excluded from the study, since a consensus on their treatment was previously reached.

In statistical comparisons between groups, a t-test was used for continuously changing data, while a chi-squared test was used for discontinuous data. In all measurements, a $p$-value $<0.05$ was considered statistically significant. All statistical analyses were conducted using SPSS Statistics 24.0 (IBM SPSS Statistics for Windows, NY, USA).

\section{RESULTS}

In the 188 cases of head and neck tumors included in the study, the mean participant age was $62 \pm 11.16$ years (between $25-95$ ). 161 (85\%) of the patients were male and 27 (15\%) were female. The histology, regions, and stages of the evaluated tumors are outlined in Table 1.

In comparing the treatment decisions suggested by the tumor board with the individual clinician decisions, it was observed that individual ENT surgeon decisions changed in 64 cases (34\%) and those of radiation oncologists changed in 65 cases (34.6\%). When the rate of change according to the stages was compared, the highest was seen in stage $3(44,4 \%)$ in ENT surgeons and in stage $2(43,5 \%)$ in radiation oncologists (Figure 1).

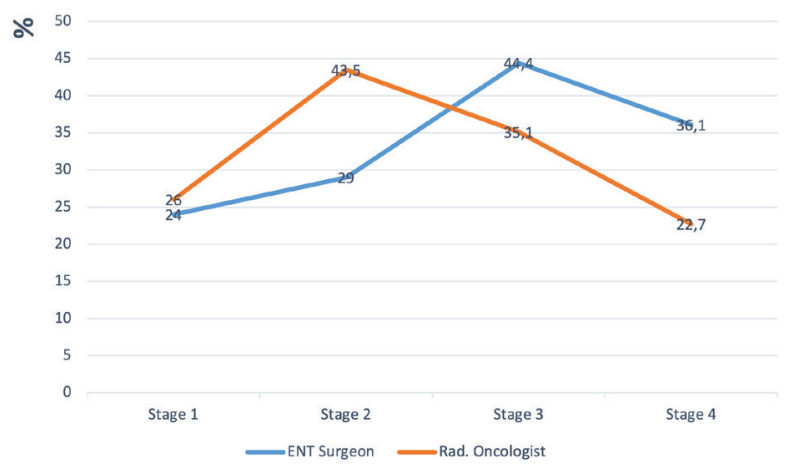

Figure 1: The rates of change of the decisions of radiation oncologists and ent surgeons according to stages. 
Table 1: Information regarding histology, region and stage of the tumors evaluated.

\begin{tabular}{|c|c|c|}
\hline & $\begin{array}{c}\text { Number } \\
\text { of tumors } \\
\text { evaluated (n) }\end{array}$ & $\begin{array}{c}\text { Percentage } \\
\text { (\%) }\end{array}$ \\
\hline \multicolumn{3}{|l|}{ A. Histology } \\
\hline Squamous Cell Carcinoma & 163 & 86.7 \\
\hline Adenocarcinoma & 1 & 0.5 \\
\hline Mucoepidermoid Carcinoma & 3 & 1.6 \\
\hline Neuroendocrine Tumor & 2 & 1.1 \\
\hline Adenoid Cystic Carcinoma & 3 & 1.6 \\
\hline Spindle Cell Carcinoma & 3 & 1.6 \\
\hline Basosquamous Carcinoma & 4 & 2.1 \\
\hline Carcinoma Ex Pleomorphic Adenom & 1 & 0.5 \\
\hline Undifferentiated Carcinoma & 4 & 2.1 \\
\hline Oncocytoma & 1 & 0.5 \\
\hline Chondrosarcoma & 2 & 1.1 \\
\hline Lymph Epidermal Tumor & 1 & 0.5 \\
\hline \multicolumn{3}{|l|}{ B. Tumor Region } \\
\hline Larynx & 115 & 61.2 \\
\hline Hypopharynx & 3 & 1.6 \\
\hline Oropharynx & 6 & 3.2 \\
\hline Oral Cavity & 28 & 14.9 \\
\hline Paranasal Sinuses & 5 & 2.7 \\
\hline Skin & 12 & 6.4 \\
\hline Nasopharynx & 7 & 3.7 \\
\hline Salivary Glands & 7 & 3.7 \\
\hline Neck Metastasis of Unknown Origin & 5 & 2.7 \\
\hline \multicolumn{3}{|l|}{ C. Tumor Stage } \\
\hline Stage 1 & 50 & 26.5 \\
\hline Stage 2 & 62 & 32.9 \\
\hline Stage 3 & 54 & 28.7 \\
\hline Stage 4 & 22 & 11.7 \\
\hline
\end{tabular}

A comparison of the initial treatment preferences of ENT surgeons with the recommendations given by the tumor board according to tumor stage is detailed in Table 2. The rate of change in the decisions of ENT surgeons at all tumor stages was statistically significant ( $p$-value at Stage $4=0.011, p$-value at other stages <0.001).

Comparisons of the initial treatment preferences of radiation oncologists with those recommended by the tumor board based on tumor stage are provided in detail in Table 3. Similarly, the rate of change in the decisions of radiation oncologists at all tumor stages was found to be statistically significant ( $p$-value at Stage $4=0.011, p$-value at other stages $<0.001$ ).

\section{DISCUSSION}

Treating head and neck cancers is a complex process that can be affected by the tumor pathology, cancer stage, and the patient's general condition $(3,7,10)$. Given the diversity of treatment options, such as surgery, radiotherapy, chemotherapy or combined therapy, the role of the multidisciplinary approach in this process is significant (9, 11). In addition, after the treatment of the primary disease, the opinions of speech therapists, nutritionists, dentists, and psychologists about treating potential comorbidities are invaluable (11). For this reason, tumor boards, which enable a more practical application of the multidisciplinary approach by gathering clinicians of different specialties and allow a rapid exchange of ideas, lead to more efficient treatment decisions. It is also known that tumor boards can influence the decisions of individual specialists (4).

The compliance of decisions made at tumor board meetings with treatment preferences of individual specialists has been studied before, but research is limited about treatment decision compliance according to tumor stage in head and neck cancers. In their study, Markus et al. (2) compared tumor board decisions with the pre-meeting decisions of surgeons and oncologists about 172 head and neck cancer patients and observed changes in pre-meeting preferences for 52 patients (30\%). In another study evaluating pediatric cancer patients discussed at tumor board meetings, it was shown that proposed treatment options changed following meetings in $35 \%$ of cases (12). Similar to the studies in the literature, a $34 \%$ change in proposed treatment decisions following board meetings was observed in the current study. A change over 30 percent is a significant difference. Specialists tend to prefer treatment procedures in their field of expertise. In this study, oncologists emphasized the rt option more frequently in their first choice at all stages and it was observed that surgeons preferred the ct and crt option less in their first choice. In our study, these decisions come to the fore especially at stage 2 for radiation oncologists and at stage 3 for ENT surgeons.

In Markus et al. (2), it was observed that the treatment preferences of medical or radiation oncologists were more likely to change after board meetings than those of oncology surgeons. In addition, regardless of squamous cell carcinoma or skin malignancies, the initial treatment choices of medical or radiation oncologists did not include surgical intervention, and the rate of change in their decisions after board meetings was statistically significant. The findings of the current study demonstrate that radiation oncologists initially preferred radiotherapy for early disease stages, but the rate of change in their decisions after tumor board meetings was found statistically significant.

Although the influence of tumor boards' recommendations on the individual preferences of clinicians is known, there is limited evidence for the effectiveness of these decisions on treatment outcomes $(10,13,14)$. A meta-analysis in the 
Table 2: The comparison of initial treatment preferences of ENT surgeons with tumor board decisions according to tumor stage.

\begin{tabular}{|c|c|c|c|c|c|c|c|c|c|}
\hline \multirow{2}{*}{ Stage } & & & \multirow{2}{*}{ Total } & \multicolumn{5}{|c|}{ Tumor board recommendation } & \multirow{2}{*}{$\begin{array}{c}\text { Change rates } \\
\mathrm{n}(\%)\end{array}$} \\
\hline & & & & Surgery & RT & CRT & Follow-up & Additional test & \\
\hline \multirow[t]{6}{*}{ Stage 1} & \multirow{5}{*}{$\begin{array}{l}\text { ENT surgeon } \\
\text { preference }\end{array}$} & Surgery & 11 & 8 & 3 & 0 & 0 & 0 & $3(27.2)$ \\
\hline & & $\mathrm{RT}$ & 28 & 3 & 22 & 2 & 0 & 1 & $6(21.4)$ \\
\hline & & CRT & 1 & 1 & 0 & 0 & 0 & 0 & $1(100)$ \\
\hline & & Follow-up & 9 & 2 & 0 & 0 & 7 & 0 & $2(22.2)$ \\
\hline & & Additional test & 1 & 0 & 0 & 0 & 0 & 1 & $0(0)$ \\
\hline & Total & & 50 & 14 & 25 & 2 & 7 & 2 & $12(24)$ \\
\hline \multirow[t]{6}{*}{ Stage 2} & \multirow{5}{*}{$\begin{array}{l}\text { ENT surgeon } \\
\text { preference }\end{array}$} & Surgery & 33 & 28 & 4 & 1 & 0 & 0 & $5(15.1)$ \\
\hline & & RT & 6 & 0 & 3 & 2 & 0 & 1 & $3(50)$ \\
\hline & & CRT & 3 & 2 & 0 & 0 & 0 & 1 & $3(100)$ \\
\hline & & Follow-up & 17 & 1 & 5 & 0 & 9 & 2 & $8(47)$ \\
\hline & & Additional test & 3 & 1 & 0 & 0 & 0 & 2 & $1(33.3)$ \\
\hline & Total & & 62 & 32 & 12 & 3 & 9 & 6 & $18(29)$ \\
\hline \multirow[t]{6}{*}{ Stage 3} & \multirow{5}{*}{$\begin{array}{l}\text { ENT surgeon } \\
\text { preference }\end{array}$} & Surgery & 28 & 17 & 2 & 7 & 0 & 2 & $11(39.2)$ \\
\hline & & RT & 13 & 3 & 7 & 3 & 0 & 0 & $6(46.1)$ \\
\hline & & CRT & 6 & 1 & 1 & 4 & 0 & 0 & $2(33.3)$ \\
\hline & & Follow-up & 5 & 0 & 4 & 0 & 1 & 0 & $4(80)$ \\
\hline & & Additional test & 2 & 0 & 1 & 0 & 0 & 1 & $1(50)$ \\
\hline & Total & & 54 & 21 & 15 & 14 & 1 & 3 & $24(44.4)$ \\
\hline \multirow[t]{5}{*}{ Stage 4} & \multirow{4}{*}{$\begin{array}{l}\text { ENT surgeon } \\
\text { preference }\end{array}$} & Surgery & 6 & 4 & 0 & 2 & 0 & 0 & $2(33.3)$ \\
\hline & & $\mathrm{RT}$ & 7 & 0 & 4 & 3 & 0 & 0 & $3(42.8)$ \\
\hline & & CRT & 8 & 0 & 2 & 6 & 0 & 0 & $2(25)$ \\
\hline & & Additional test & 1 & 0 & 0 & 1 & 0 & 0 & $1(100)$ \\
\hline & Total & & 22 & 4 & 6 & 12 & 0 & 0 & $8(36.1)$ \\
\hline \multirow[t]{6}{*}{ Total } & \multirow{5}{*}{$\begin{array}{l}\text { ENT surgeon } \\
\text { preference }\end{array}$} & Surgery & 78 & 57 & 9 & 10 & 0 & 2 & $21(26.9)$ \\
\hline & & $\mathrm{RT}$ & 54 & 6 & 36 & 10 & 0 & 2 & $18(33.3)$ \\
\hline & & CRT & 18 & 4 & 3 & 10 & 0 & 1 & $8(44.4)$ \\
\hline & & Follow-up & 31 & 3 & 9 & 0 & 17 & 2 & $14(45.1)$ \\
\hline & & Additional test & 7 & 1 & 1 & 1 & 0 & 4 & $3(42.8)$ \\
\hline & Total & & 188 & 71 & 58 & 31 & 17 & 11 & $64(34)$ \\
\hline
\end{tabular}

The initial preferences of ENT surgeons have changed in 64 patients (34\%). ( $p=0.011$ in Stage $4, p<0.001$ in other stages)

literature investigating tumor board decisions over a span of approximately 20 years emphasized that the rate of change in decisions was between $4 \%$ and $45 \%$ after tumor board meetings, but there was not enough evidence to substantiate that the revised decisions led to better treatment (14). In this meta-analysis, only one study about head and neck tumors was examined, and the rate of change was reported as $27 \%$ (15). In their study, Boxer et al. (13) reviewed the outcomes of 504 lung cancer patients discussed at tumor board meetings, out of 988 patients referred to their clinic. They concluded that tumor board decisions provided treatment modalities that increased quality of life but did not alter life expectancy. Large patient cohorts and attentive planning are required to evaluate the long-term effects of individual treatment approaches and recommendations given by tumor boards for patients with head and neck cancers.

Considering cost and treatment effectiveness, some authors argue that only advanced head and neck cancers should be discussed at tumor board meetings. In addition, they also suggest that the board recommendations for early-stage malignancies do not have significant superiority over individual clinician decisions $(7,10)$. Contrary to these views, the findings obtained in this study suggest that there was a statistically significant difference between the treatment approaches of tumor boards and individual specialists, including those for early-stage head and neck cancer patients. 
Table 3: The comparison of initial treatment preferences of radiation oncologists with tumor board decisions according to tumor stage.

\begin{tabular}{|c|c|c|c|c|c|c|c|c|c|}
\hline \multirow{2}{*}{ Stage } & & & \multirow{2}{*}{ Total } & \multicolumn{5}{|c|}{ Tumor board recommendation } & \multirow{2}{*}{$\begin{array}{c}\text { Change rates } \\
n(\%)\end{array}$} \\
\hline & & & & Surgery & RT & CRT & Follow-up & Additional test & \\
\hline \multirow[t]{6}{*}{ Stage 1} & \multirow{5}{*}{$\begin{array}{l}\text { Radiation } \\
\text { oncologist } \\
\text { preference }\end{array}$} & Surgery & 10 & 7 & 3 & 0 & 0 & 0 & $3(30)$ \\
\hline & & RT & 28 & 5 & 21 & 1 & 0 & 1 & $7(25)$ \\
\hline & & CRT & 1 & 0 & 0 & 1 & 0 & 0 & $0(0)$ \\
\hline & & Follow-up & 10 & 2 & 1 & 0 & 7 & 0 & $3(30)$ \\
\hline & & Additional test & 1 & 0 & 0 & 0 & 0 & 1 & $0(0)$ \\
\hline & Total & & 50 & 14 & 25 & 2 & 7 & 2 & $13(26)$ \\
\hline \multirow[t]{5}{*}{ Stage 2} & \multirow{4}{*}{$\begin{array}{l}\text { Radiation } \\
\text { oncologist } \\
\text { preference }\end{array}$} & Surgery & 14 & 14 & 0 & 0 & 0 & 0 & $0(0)$ \\
\hline & & $\mathrm{RT}$ & 32 & 16 & 11 & 2 & 1 & 2 & $21(65.6)$ \\
\hline & & CRT & 4 & 2 & 0 & 1 & 0 & 1 & $2(50)$ \\
\hline & & Follow-up & 12 & 0 & 1 & 0 & 8 & 3 & $4(33.3)$ \\
\hline & Total & & 62 & 32 & 12 & 3 & 9 & 6 & $27(43.5)$ \\
\hline \multirow[t]{6}{*}{ Stage 3} & \multirow{5}{*}{$\begin{array}{l}\text { Radiation } \\
\text { oncologist } \\
\text { preference }\end{array}$} & Surgery & 21 & 15 & 0 & 5 & 0 & 1 & $6(28.5)$ \\
\hline & & $\mathrm{RT}$ & 15 & 3 & 11 & 1 & 0 & 0 & 4 (26.6) \\
\hline & & CRT & 14 & 3 & 1 & 8 & 1 & 1 & $6(42.8)$ \\
\hline & & Follow-up & 3 & 0 & 3 & 0 & 0 & 0 & $3(100)$ \\
\hline & & Additional test & 1 & 0 & 0 & 0 & 0 & 1 & $0(0)$ \\
\hline & Total & & 54 & 21 & 15 & 14 & 1 & 3 & 19 (35.1) \\
\hline \multirow[t]{4}{*}{ Stage 4} & \multirow{3}{*}{$\begin{array}{l}\text { Radiation } \\
\text { oncologist } \\
\text { preference }\end{array}$} & Surgery & 3 & 2 & 0 & 1 & 0 & 0 & $1(33.3)$ \\
\hline & & RT & 8 & 0 & 6 & 2 & 0 & 0 & $2(25)$ \\
\hline & & CRT & 11 & 2 & 0 & 9 & 0 & 0 & $2(18.1)$ \\
\hline & Total & & 22 & 4 & 6 & 12 & 0 & 0 & $5(22.7)$ \\
\hline \multirow[t]{6}{*}{ Total } & \multirow{5}{*}{$\begin{array}{l}\text { Radiation } \\
\text { oncologist } \\
\text { preference }\end{array}$} & Surgery & 48 & 38 & 3 & 6 & 0 & 1 & $10(20.8)$ \\
\hline & & $\mathrm{RT}$ & 83 & 24 & 49 & 6 & 1 & 3 & 34 (40.9) \\
\hline & & CRT & 30 & 7 & 1 & 19 & 1 & 2 & $11(36.6)$ \\
\hline & & Follow-up & 25 & 2 & 5 & 0 & 15 & 3 & $10(40)$ \\
\hline & & Additional test & 2 & 0 & 0 & 0 & 0 & 2 & $0(0)$ \\
\hline & Total & & 188 & 71 & 58 & 31 & 17 & 11 & $65(34.6)$ \\
\hline
\end{tabular}

The initial preferences of radiation oncologists have changed in 65 patients (34,6\%). ( $p=0.001$ in Stage $4, p<0.001$ in other stages)

\section{CONCLUSION}

This study investigated the effectiveness of tumor boards by comparing individual treatment preferences of ENT surgeons and radiation oncologists with the recommendations made in tumor boards for patients diagnosed with head and neck cancers. The aim of this study was not to evaluate the outcomes of doctors' treatment decisions, but rather to investigate the compatibility of their preferred treatment options with those of the tumor board as a whole. It should be noted that results may vary depending on individual treatment centers according to clinician experience and the clinics' technical allowances. In light of our findings, we emphasize the importance of tumor boards in practicing a multidisciplinary clinical approach and evaluating all cancer patients, including early-stage patients.
Ethics Committee Approval: All procedures performed in studies involving human participants were in accordance with the ethical standards of the institutional research committee (University of Health Sciences Samsun Education and Research Hospital Clinical Research Ethics Committee dated 13.02.2020 and numbered 2020/0213) and with the 1964 Helsinki declaration and its later amendments or comparable ethical standards.

Informed Consent: Informed consent was obtained from all individual participants included in the study.

Peer-Review: Externally peer-reviewed.

Author Contributions: Conception/Design of Study- G.A., N.F.T., M.D.M., S.A., A.Ö.; Data Acquisition- G.A., N.F.T., M.D.M., S.A., A.Ö.; Data Analysis/Interpretation- G.A., N.F.T., M.D.M., S.A., A.Ö.; 
Drafting Manuscript- G.A., N.F.T., M.D.M., S.A., A.Ö.; Critical Revision of Manuscript- G.A., N.F.T., M.D.M., S.A., A.Ö.; Final Approval and Accountability- G.A., N.F.T., M.D.M., S.A., A.Ö.

Conflict of Interest: Authors declared no conflict of interest.

Financial Disclosure: Authors declared no financial support.

\section{REFERENCES}

1. Bray F, Ferlay J, Soerjomataram I, Siegel RL, Torre LA, Jemal A. Global cancer statistics 2018: GLOBOCAN estimates of incidence and mortality worldwide for 36 cancers in 185 countries. CA Cancer J Clin 2018;68:394-424.

2. Brunner M, Gore SM, Read RL, Alexander A, Mehta A, Elliot M, et. al. Head and Neck Multidisciplinary Team Meetings: Effect on Patient Management. Head Neck 2015;37(7):1046-50.

3. Eskander A, Irish J, Groome PA, Freeman J, Gullane P, Gilbert R, et al. Volume-outcome relationships for head and neck cancer surgery in a universal health care system. Laryngoscope 2014;124:2081-8.

4. Bozec A, Culi e D, Poissonnet G, Dassonville O. Current role of primary surgical treatment in patients with head and neck squamous cell carcinoma. Curr Opin Oncol 2019;31(3):138e145.

5. Lee VHF, Chan JYW, Vardhanabhuti V, Kwong DLW, Leung TW, Chan SY, et al. Advancing Care for Head and Neck Cancers in a Multidisciplinary Tumour Board in the East. Clin Oncol (R Coll Radiol) 2019;31(8):549-59.

6. Guy JB, Benna M, Xia Y, Daguenet E, Ben Mrad M, Jmour O, et al. Quality Insurance in Head and Neck Cancer Multidisciplinary Team Meetings: A Watchful Eye on Real-Life Experience. Oral Oncol 2019;91:35-8.
7. Nguyen NP, Vos P, Lee H, Borok TL, Karlsson U, Martinez T, et al. Impact of Tumor Board Recommendations on Treatment Outcome for Locally Advanced Head and Neck Cancer. Oncology 2008;75(34):186-91.

8. Aquinas T. Prologue. In: On being and essence. Pontifical Institute on Mediaeval Studies; 1968. p.1. Translated by Armand Maurer.

9. Westin T, Stalfors J. Tumour boards/multidisciplinary Head and Neck Cancer Meetings: Are They of Value to Patients, Treating Staff or a Political Additional Drain on Healthcare Resources? Curr Opin Otolaryngol Head Neck Surg 2008;16(2):103-7.

10. Mullan BJ, Brown JS, Lowe D, Rogers SN, Shaw RJ. Analysis of Time Taken to Discuss New Patients With Head and Neck Cancer in Multidisciplinary Team Meetings. Br J Oral Maxillofac Surg 2014;52(2):128-33.

11. Haddad R, Annino D, Tishler RB. Multidisciplinary approach to cancer treatment: focus on head and neck cancer. Dent Clin North Am 2008;52(1):1-17.

12. Thenappan A, Halaweish I, Mody RJ, Smith EA, Geiger JD, Ehrlich PF, et.al. Review at a Multidisciplinary Tumor Board Impacts Critical Management Decisions of Pediatric Patients With Cancer. Pediatr Blood Cancer 2017;64(2):254-8.

13. Boxer MM, Vinod SK, Shafiq J, Duggan KJ. Do Multidisciplinary Team Meetings Make a Difference in the Management of Lung Cancer? Cancer 2011;117(22):5112-20.

14. Pillay B, Wootten AC, Crowe H, Corcoran N, Tran B, Bowden P, et. al. The impact of multidisciplinary team meetings on patient assessment, management and outcomes in oncology settings: A systematic review of the literature. Cancer Treat Rev 2016;42:56-72.

15. Wheless SA, McKinney KA, Zanation AM. A prospective study of the clinical impact of a multidisciplinary head and neck tumor board. Otolaryngol Head Neck Surg 2010;143(5):650-4. 